\title{
BLOCOS DE CONCRETO COM RESÍDUOS DE PET: ALTERNATIVA PARA SUSTENTABILIDADE URBANA
}

\author{
Concrete blocks with Polyethylene Terephthalate (PET) waste: \\ Alternative to Urban Sustainability
}

\section{Bloques de hormigón con residuos de tereftalato de polietileno (PET): alternativa para la sostenibilidad urbana}

Recebido em 01/05/2021 Aceito em 07/07/2021

SCHILIVE, Pâmella Mirélla de Souza

CALLEJAS, Ivan Julio Apolonio ${ }^{2}$ DURANTE, Luciane Cleonice ${ }^{3}$ GUARDA, Emeli Lalesca Aparecida da ${ }^{4}$

\footnotetext{
${ }^{1}$ Pós-graduanda em Desenvolvimento Urbano pelo Instituto Federal de Educação, Ciência e Tecnologia de Mato Grosso, Campus Várzea Grande, Mato Grosso, Brasil. pamella_schilive@hotmail.com ORCID: 0000-0003-3172-3618
${ }^{2}$ Departamento de Arquitetura e Urbanismo, Faculdade de Arquitetura, Engenharia e Tecnologia, Universidade Federal do Mato Grosso. Cuiabá, Mato Grosso, Brasil. ivancallejas1973@gmail.com ORCID: 0000-0001-7877-7029

${ }^{3}$ Departamento de Arquitetura e Urbanismo, Faculdade de Arquitetura, Engenharia e Tecnologia, Universidade Federal do Mato Grosso. Cuiabá, Mato Grosso, Brasil. luciane.durante@hotmail.com ORCID: 0000-0002-4998-4587
}

\footnotetext{
${ }^{4}$ Programa de Pós-graduação em Arquitetura e Urbanismo, Universidade Federal de Santa Catarina. Florianópolis, Santa Catarina, Brasil. emeliguarda@gmail.com ORCID: 0000-0001-7536-4448
} 


\title{
Resumo
}

A reciclagem é uma alternativa ambientalmente adequada para a destinação de resíduos sólidos urbanos, considerando a produção de materiais da indústria da construção civil. Objetiva-se demonstrar a viabilidade técnica da produção de concretos secos com incorporação de resíduos de polietileno tereftalato (PET) para a fabricação de blocos de concreto vazados. Seguiram-se as seguintes etapas metodológicas: estudo de dosagem, confecção de corpos de prova com concreto seco com substituição da areia industrial por resíduo de PET nos percentuais de 0, 5, 10 e 15\%; avaliação das propriedades físico-mecânicas dos corpos de prova; produção e avaliação dos blocos de referência e com substituição de areia por flakes de PET. A introdução progressiva de PET na matriz cimentícia elevou a absorção de água e do índice de vazios nos traços, reduzindo a massa específica e a resistência à compressão. Por meio da correlação entre o percentual de substituição de PET e resistência mecânica à compressão, determinou-se que a incorporação de PET no traço deveria ser reduzida a 7\%, para atendimento aos requisitos da NBR 6136. A reciclagem de PET é tecnicamente viável para produção de blocos de concreto, evitando sua destinação a áreas ilegais e aterros, contribuindo com a sustentabilidade urbana.

Palavras-Chave: Resíduos sólidos, Resíduos poliméricos, Reciclagem, Sustentabilidade urbana

\begin{abstract}
Recycling is an environmentally suitable alternative for the disposal of urban solid waste, considering the production of materials from the civil construction industry. This article aims to demonstrate the technical feasibility of producing dry concrete with the incorporation of polyethylene terephthalate (PET) waste for the manufacture of simple hollow concrete blocks. The methodological steps are dosage study, preparation of specimens with dry concrete from the replacement of industrial sand by PET waste in the percentages of 0, 5, 10 and 15\%; evaluation of physical and mechanical properties of specimens; and production of reference blocks and replacement of sand by PET flakes; evaluation of the physical and mechanical properties of the blocks. The progressive introduction of PET in the cementitious matrix increased the water absorption and void ratio in the mixes, reducing the specific mass and compressive strength. Through the correlation between the percentage of PET replacement and compression mechanical resistance, it was determined that the percentage of PET incorporation in the mix should be reduced to $7 \%$ to meet the physical and mechanical requirements established by NBR 6136. PET is technically viable for concrete blocks production, avoiding its destination to illegal areas and landfills, contributing to urban sustainability.
\end{abstract}

Key-Words: Solid waste, Polymeric waste, Recycling, Urban sustainability

\section{Resumen}

El reciclaje es una alternativa ambientalmente adecuada para la disposición de residuos sólidos urbanos, considerando la producción de materiales de la industria de la construcción. El objetivo es demostrar la viabilidad técnica de producir hormigón seco con la incorporación de residuos de tereftalato de polietileno (PET) para la fabricación de bloques de hormigón hueco. Se siguieron los siguientes pasos metodológicos: estudio de dosificación, preparación de probetas con hormigón seco con sustitución de arena industrial por residuos de PET en los porcentajes de 0, 5, 10 y 15\%; evaluación de propiedades físico-mecánicas de probetas; producción y evaluación de bloques de referencia y con sustitución de arena por escamas de PET. La introducción progresiva de PET en la matriz cementosa aumentó la absorción de agua y la relación de vacíos en las mezclas, reduciendo la masa especifica y la resistencia a la compresión. Mediante la correlación entre el porcentaje de reposición de PET y la resistencia mecánica a la compresión, se determinó que la incorporación de PET en la mezcla debe reducirse al 7\%, con el fin de cumplir con los requisitos de NBR 6136. El reciclaje de PET es técnicamente viable para la producción de bloques de hormigón, evitando su destino a zonas ilegales, contribuyendo a la sostenibilidad urbana.

Palabras clave: Residuos sólidos, Residuos poliméricos, Reciclaje, Sostenibilidad urbana. 


\section{Introdução}

O gerenciamento responsável dos resíduos sólidos gerados nas cidades, sejam eles industriais, comerciais, domésticos ou ainda provenientes da construção e/ou demolição de edificações, tem sido um desafio para a gestão pública no Brasil, uma vez que a sua inadequada destinação causa degradação da paisagem urbana, ocupação de vias e logradouros públicos, poluição dos mananciais, assoreamento de rios e córregos, contaminação do solo, obstrução dos sistemas de drenagem urbana, dentre outros (BRASIL,2010; AGOPYAN e JHON, 2011; LU e TAM, 2013).

A reciclagem é uma das possibilidades ambientalmente adequada para a destinação correta de resíduos (BRASIL, 2002) que concilia tanto o desenvolvimento sustentável e econômico, quanto o social, visto que se torna uma alternativa para a geração de empregos. Na indústria da construção civil, responsável por $40 \%$ de todos os resíduos gerados nas cidades (PNUD, 2012), a reciclagem traz vários benefícios, com reflexo direto na redução no consumo de recursos naturais não renováveis, podendo, desta maneira, contribuir para assegurar padrões de produção e de consumo mais sustentáveis, alinhados com a Agenda 2030 (ONU, 2015), em especial com a ODS 3 (Saúde e BemEstar), a 11 (Cidades e Comunidades Sustentáveis) e a 13 (Combate às Alterações Climáticas).

Já existem alternativas de utilização de resíduos sólidos gerados no meio urbano como matéria prima para a produção de argamassas, de tijolos ou blocos de concreto para sistemas de vedação vertical, de telhas para o sistema de cobertura entre outros (DAMASCENO et al., 2015; CARDOSO, 2017; GOMES et al., 2017; CALLEJAS, DURANTE e OLIVEIRA, 2017 e PAVLU et al., 2019). Em se tratando do resíduo de Polietileno Tereftalato (PET), um material inerte, resistente, de baixa densidade e condutividade térmica (NAVARRO et al., 2008), este se torna propício para incorporação em materiais de construção, como insumo para concretos e argamassas. Porém, soluções técnicas com a sua utilização ainda são pouco exploradas.

No Brasil, em 2015, foram produzidas mais de 537 mil toneladas de PET, sendo que apenas $51 \%$ foram reaproveitadas para a produção de embalagens, lâminas e chapas e na produção têxtil (ABIPET, 2015). A baixa taxa de reciclagem está relacionada a falta de coleta e destinação adequada, e também, aos maus hábitos da população, que usualmente não realiza a coleta seletiva, destinando grande quantidade desse material reciclável para os aterros sanitários.

Assim, levando-se em consideração a crescente necessidade de redução de resíduos sólidos lançados nas cidades, este trabalho objetiva demonstrar a viabilidade técnica da substituição do agregado miúdo industrial por flakes de resíduos de polietileno tereftalato (PET), em misturas de concretos secos destinados a fabricação de blocos de concreto simples do tipo vazado. Pretende-se, com isso, demonstrar a viabilidade da incorporação desse resíduo na cadeia produtiva da indústria da construção civil, visando agregar valor econômico ao produto e gerar uma alternativa técnica para absorver e/ ou reduzir o passivo ambiental da cadeia produtiva do PET, evitando sua destinação para áreas ilegais ou aterros sanitários, corroborando, desta forma, com a sustentabilidade urbana.

\section{Materiais e Métodos}

A pesquisa desenvolve-se em três etapas: a) caracterização dos traços de concreto com substituição parcial de flakes de PET; b) estudo do traço; e, c) fabricação dos blocos, em parceria com uma indústria de produção de artefatos de concreto, planejada conforme apresentado na Figura 1. 
Figura 1: Esquema do planejamento experimental da pesquisa.

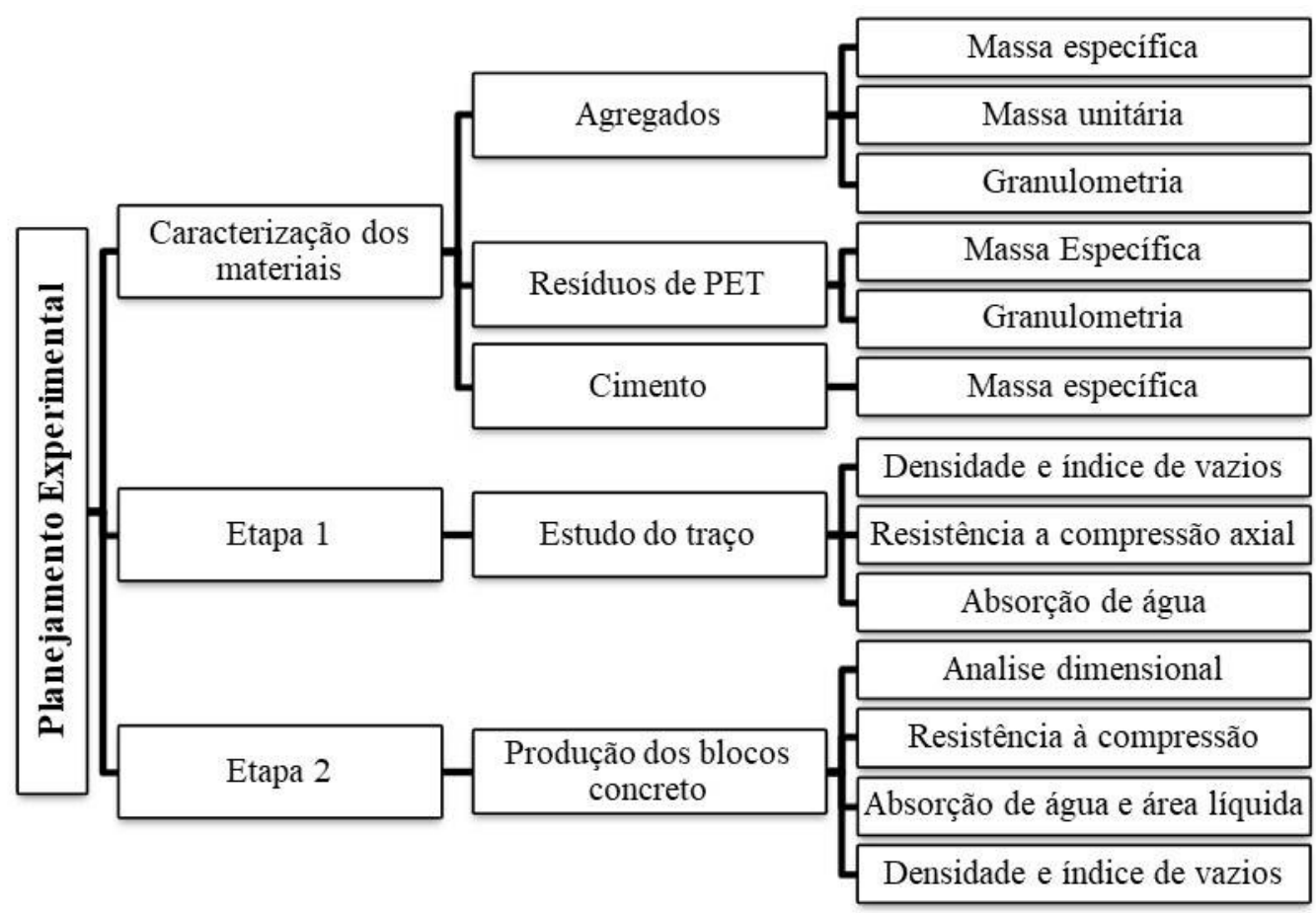

Fonte: os autores

\subsection{Caracterização dos materiais}

Os materiais utilizados como insumo para a fabricação dos blocos de concreto são flakes de PET, areia, brita 0 , pó de pedra e cimento.

A areia e brita 0 (pedrisco) empregados nos blocos de concreto são de origem graníticas, extraídas em jazida localizada a $60 \mathrm{~km}$ da cidade de Cuiabá, Mato Grosso. O pó de pedra é de origem calcária, obtido em jazida localizada no perímetro urbano da cidade. O resíduo de PET é proveniente do processo de moagem de garrafas de bebida pós-consumo na forma de flakes, obtido em recicladora localizada no distrito industrial da cidade.

Com o objetivo de conhecer as propriedades dos agregados, amostras da areia, pedrisco e pó de pedra foram submetidas aos seguintes ensaios para caracterização: redução da amostra de campo NBR NM 27 (ABNT, 2001); análise de composição granulométrica - NBR NM 248 (ABNT, 2003); massa unitária no estado solto - NBR NM 45 (ABNT, 2005), massa específica - NBR NM 52 (ABNT, 2009) e NBR NM 53 (ABNT, 2009). Com vistas à realização desses ensaios, realizou-se o processo de redução das amostras conforme NBR NM 27 (ABNT, 2001).

Para determinação da granulometria do miúdo de PET foram utilizadas as peneiras da série normal e intermediária, com material agitado de forma manual (NBR NM248, ABNT 2003). Para determinação da sua massa específica, utilizou-se o método do Frasco de Chapman (NBR 9776, ABNT 1987), uma vez que o método vigente seria inadequado para esse material, pois emprega estufa em altas temperaturas no seu procedimento. Nesse caso, devido o PET possuir massa unitária inferior à da água (líquido padrão do ensaio), esta foi substituída por álcool etílico, permitindo que o ensaio fosse realizado de forma adequada. Por possuir propriedades hidrofóbicas, o PET não absorve água e tornase desnecessário determinar seu índice de absorção de água. As propriedades físicas dos materiais utilizados como insumos para a produção do bloco podem ser observadas no Quadro 1. 
Quadro 1: Caracterização dos agregados utilizados na pesquisa.

\begin{tabular}{|c|c|c|c|}
\hline Agregado & Ensaios & Valores obtidos & Imagem \\
\hline \multirow{4}{*}{$\begin{array}{c}\text { Areia } \\
\text { Artificial }\end{array}$} & Massa específica $\left(\mathrm{g} / \mathrm{cm}^{3}\right)$ & 2,12 & \\
\hline & Massa unitária $\left(\mathrm{g} / \mathrm{cm}^{3}\right)$ & 1,13 & \\
\hline & Diâmetro máximo característico (mm) & 2,36 & \\
\hline & Módulo de finura & 2,16 & \\
\hline \multirow{4}{*}{ Brita 0} & Massa específica $\left(\mathrm{g} / \mathrm{cm}^{3}\right)$ & 2,04 & \\
\hline & Massa unitária $\left(\mathrm{g} / \mathrm{cm}^{3}\right)$ & 1,155 & \\
\hline & Diâmetro máximo característico $(\mathrm{mm})$ & 9,5 & \\
\hline & Módulo de finura & 5,42 & \\
\hline \multirow{4}{*}{ Pó de pedra } & Massa específica $\left(\mathrm{g} / \mathrm{cm}^{3}\right)$ & 2,20 & \\
\hline & Massa unitária $\left(\mathrm{g} / \mathrm{cm}^{3}\right)$ & 1,37 & \\
\hline & Diâmetro máximo característico $(\mathrm{mm})$ & 4,75 & \\
\hline & Módulo de finura & 2,55 & \\
\hline \multirow{3}{*}{ PET } & Massa específica $\left(\mathrm{g} / \mathrm{cm}^{3}\right)$ & 1,33 & \\
\hline & Diâmetro máximo característico $(\mathrm{mm})$ & 2,36 & \\
\hline & Módulo de finura & 3,79 & \\
\hline
\end{tabular}

Fonte: os autores

O módulo de finura da areia industrial é 2,16, caracterizando-a como fina, com curva granulométrica dentro da zona ótima segundo a NBR 7211 (ABNT, 2009) (Figura 2a). Já o pedrisco apresenta mais que $2 \%$ de material passante na peneira de abertura de malha de 4,75 . A sua curva granulométrica se encontra fora dos limites da zona granulométrica (Figura 2b), mas optou-se por mantê-lo, em função de ser o único disponibilizado pela empresa fabricante do bloco.

Figura 2: Curvas granulométricas: (a) areia (b) brita 0, (c) pó-de-pedra e (d) flakes de PET.

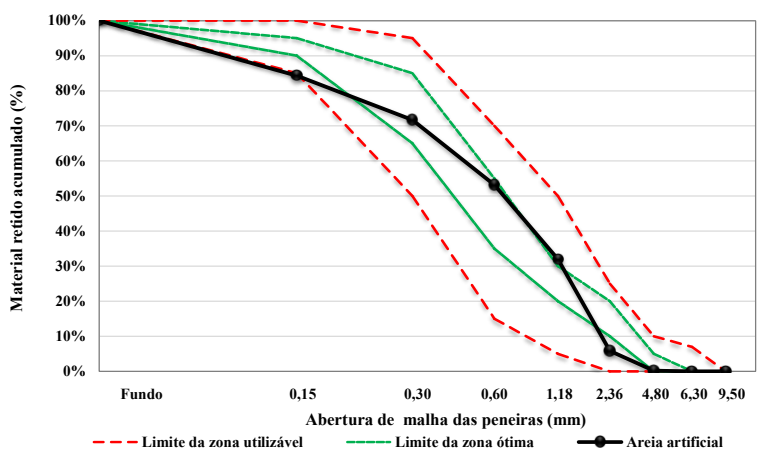

(a)

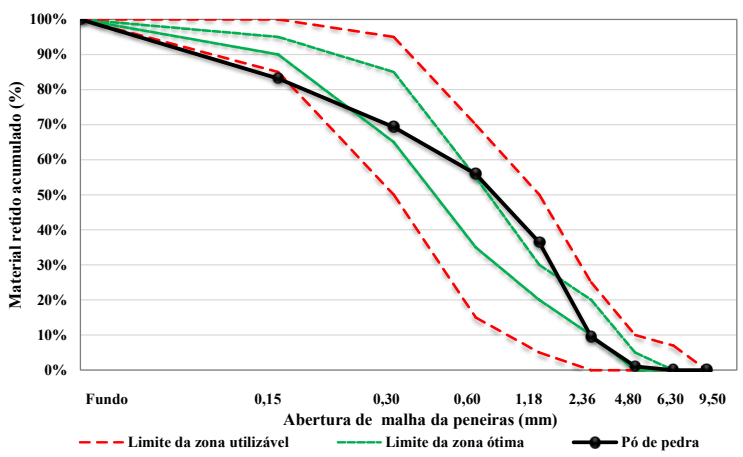

(c)

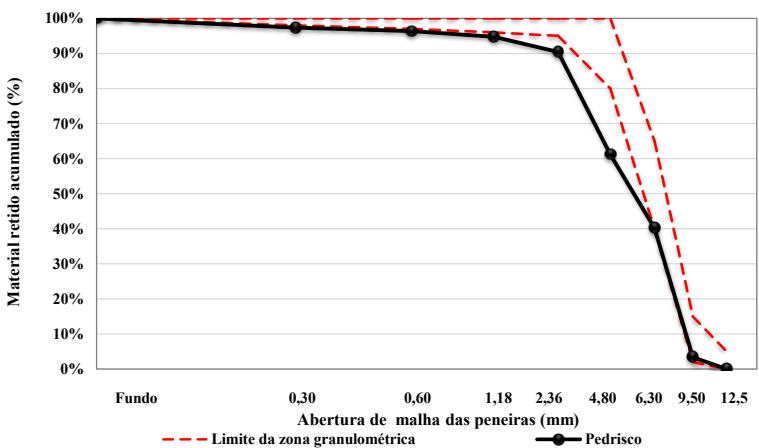

(b)

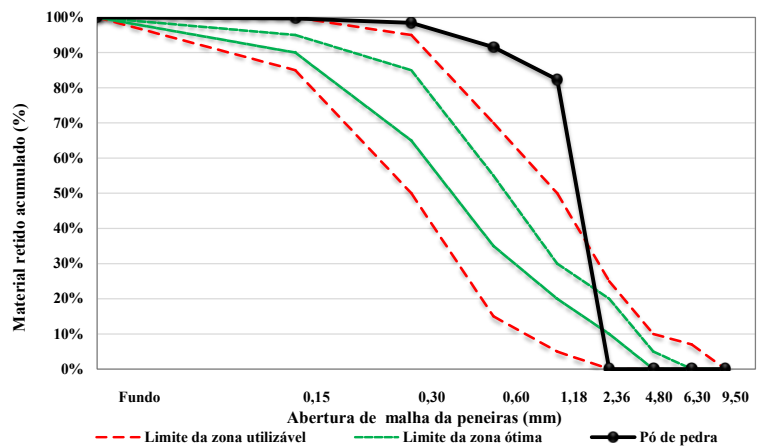

(d)

Fonte: Os autores 
O módulo de finura do pó de pedra é de 2,55, com curva granulométrica inserida dentro dos limites de zona ótima segundo a NBR 7211 (ABNT, 2009) (Figura 2c). Para os flakes de PET, o módulo de finura é de 3,79, superior ao da areia, e sua densidade é inferior, com sua curva granulométrica fora dos limites da zona utilizável em virtude de seu formato, o que não caracteriza uma não conformidade.

O cimento empregado foi o Portland CPV ARI (Alta Resistência Inicial), da marca Ciplan, que permite que se atinja elevada resistência nos primeiros tempos de cura. Para a determinação da sua massa específica foi utilizado o Frasco de Le Chatelier, conforme NBR 16605 (ABNT, 2017). O valor obtido de massa específica é $3,18 \mathrm{~g} / \mathrm{cm}^{3}$, resultante da média de duas determinações. Foram realizados ensaios de determinação da resistência à compressão do cimento aos 1, 3 e 7 dias, com valores atendendo à NBR 16697 (ABNT, 2018). A água usada para produção dos blocos de concreto foi a proveniente da rede de abastecimento local (Águas Cuiabá), considerada potável, seguindo as recomendações da NBR 15900 (ABNT, 2009). O aditivo utilizado foi o CQ PRESS MIX, plastificante para concretos secos (ABNT, 2009), que tem a função reduzir a absorção de água pela mistura e dar maior fluidez a massa, conferindo maior grau de compactação ao concreto e, consequentemente, aumentando sua resistência e melhorando o acabamento das peças.

\subsection{Etapa 1: Estudo de traço}

A dosagem adequada dos traços utilizados na pesquisa baseou-se na NBR 6136 (ABNT, 2016), que impõe que o bloco sem função estrutural (classe de perfil $\mathrm{C}$ ) deve suportar carga mínima de $3 \mathrm{MPa}$ e possuir uma absorção de água inferior a $10 \%$.

A partir do levantamento de algumas pesquisas sobre o tema, percebeu-se que a incorporação de resíduos de PET proporciona redução da resistência mecânica nos traços de concretos, com queda expressiva a partir de 15\% de substituição (CAMPOS, et. al, 2014; CORREA, 2015; SILVA, 2016). Como se busca produzir blocos de concreto com a maior incorporação de flakes de PET e que ainda possam atender os requisitos normativos visando sua produção para fins comerciais, optou-se por um traço 1:19,19 para produzir blocos que alcancem 4,0 MPa (sem incorporação de PET). A partir desse traço, calculou-se a substituição de areia por resíduo de PET nos teores de 5\%, 10\% e 15\%, mantendo-se o volume. O fator água/cimento foi mantido nas misturas para tornar os traços comparáveis entre si. O cálculo da substituição desse agregado utilizou-se da Equação 1.

$$
M_{r}=V(\%) \cdot \frac{M_{a} \times \gamma_{r}}{\gamma_{a} \times 100}
$$

Onde:

$M r=$ Massa de resíduo a ser utilizada no traço $(\mathrm{g})$

$\boldsymbol{V}=$ Percentual de areia a ser substituído pelo resíduo (\%)

$M a=$ Massa total de areia no traço $(\mathrm{g})$

ya $=$ Massa específica da areia $\left(\mathrm{g} / \mathrm{cm}^{3}\right)$

$y r=$ Massa específica do resíduo $\left(\mathrm{g} / \mathrm{cm}^{3}\right)$

A Tabela 2 ilustra os traços utilizados no estudo de traço para a produção de $1 \mathrm{~m}^{3}$ de concreto. Para a etapa 2, apenas o traço que apresentou a maior percentagem de incorporação de PET e que atendeu aos requisitos normativos de desempenho físico-mecânico, foi utilizado. Com essa estratégia, busca-se absorver e/ ou reduzir o passivo ambiental da cadeia produtiva do PET, procurando minimizar sua destinação para áreas ilegais ou aterros sanitários. 
Tabela 2: Proporção em massa dos agregados utilizados para a produção dos traços unitários.

\begin{tabular}{ccccc}
\hline \multirow{2}{*}{ Materiais } & \multirow{4}{*}{ Quantidade para produzir $\mathbf{1 m}^{\mathbf{3}}$ de concreto (kg) } \\
\cline { 2 - 5 } & \multirow{2}{*}{ REF } & $\mathbf{5 \%}$ & $\mathbf{1 0 \%}$ & $\mathbf{1 5 \%}$ \\
\cline { 2 - 5 } & 106 & 106 & 516 & 106 \\
\hline Cimento & 516 & 516 & 396 & 516 \\
\hline Pó de pedra & 396 & 396 & 1066 & 396 \\
\hline Brita & 1121 & 1093 & 55 & 1038 \\
\hline Areia Industrial & 0 & 28 & 149,73 & 149,73 \\
\hline Resíduo de PET & 149,73 & 149,73 & $1: 18,67: 0,52$ & $1: 18,41: 0,78$ \\
\hline Água (Litros) & $1: 19,19$ & $1: 18,93: 0,26$ &
\end{tabular}

O traço referência foi de 1:19,19, ou seja, para cada $1 \mathrm{~kg}$ de cimento serão consumidos $19,19 \mathrm{~kg}$ de agregados, com água e aditivo na proporção de $7 \%$ e $0,3 \%$ da massa total da mistura e da massa do cimento, respectivamente. Esses parâmetros são fixos em todos os traços, variando apenas a quantidade de agregado miúdo e flakes de PET.

Foram confeccionados de forma manual 12 corpos de prova para cada traço (o de referência - sem adição de PET, mais os traços com incorporação de flakes de PET - em 5, 10 e 15\%, doravante denominados PET5, PET10 E PET15, respectivamente) (Figura 2a). De acordo com Fernandes (2016), a resistência do concreto seco tem relação direta com o grau de compactação utilizado na sua moldagem, com influência direta do tipo de máquina utilizada para confeccionar o $\mathrm{BC}$, interferindo desta forma na sua resistência final. Nesse sentido, a quantidade de camadas e número de golpes foram definidos em estudo preliminar de dosagem, onde se procurou promover o adensamento dos corpos de prova de tal forma que se simulasse o comportamento de fábrica, onde a massa é vibroprensada. A moldagem ocorreu em moldes cilíndricos de $5 \times 10 \mathrm{~cm}$, prélubrificados, onde a mistura foi compactada em quatro camadas de 30 golpes. A desmoldagem ocorreu após 24 horas (Figura 2b), e os corpos de prova foram submersos em água para a cura, até a realização dos ensaios de caracterização física e mecânica.

Figura 2: a) Processo de moldagem e b) corpos de prova desformados- traços de 5\%, 10\% e 15\% de PET.

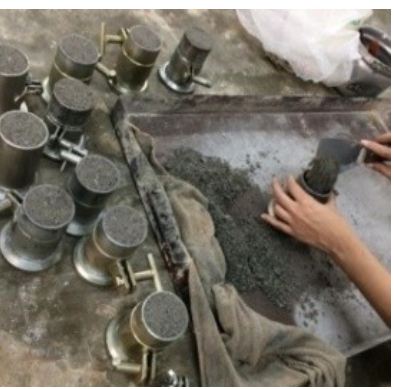

(a)

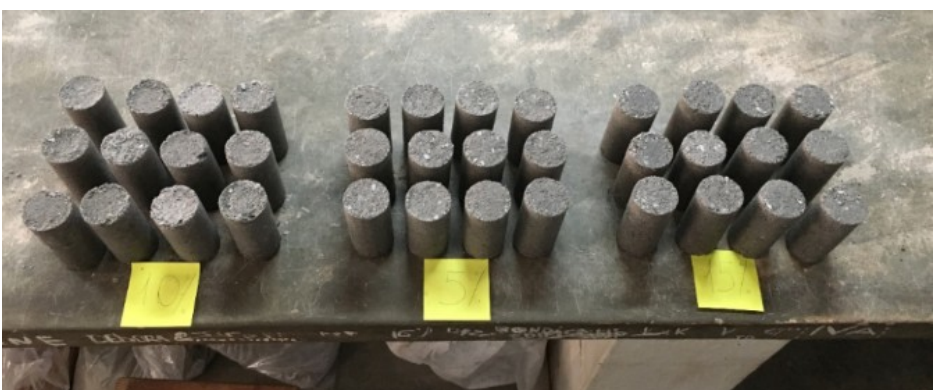

(b)

Fonte: Os autores

Aos 28 dias, realizaram-se os ensaios de massa específica $(\rho)$, absorção de água $(\alpha)$, e índice de vazios (IV) em três corpos de prova para cada traço conforme as Equações 2, 3 e 4, respectivamente:

$\rho=\frac{m 1}{m 1-m 3}$

$\alpha(\%)=\frac{m 2-m 1}{m 1} \times 100$ 
$I v(\%)=\frac{m 2-m 1}{m 2-m 3} \times 100$

Onde:

M1 = Massa seca do corpo de prova $(\mathrm{g})$

M2 = Massa do corpo de prova na condição de saturado com superfície seca $(\mathrm{g})$

M3 = Massa do corpo de prova quando imerso em água $(\mathrm{g})$

Para a determinação dos índices citados, realizou-se a secagem do corpo de prova por meio de estufa na temperatura de até $\left(110 \pm 5^{\circ} \mathrm{C}\right)$ por $24 \mathrm{~h}$, registrando-se a pesagem dessa massa seca $(\mathrm{m} 1)$. Em seguida, com os corpos de prova em temperatura ambiente, estes foram imersos em água à temperatura de $\left(23 \pm 5^{\circ} \mathrm{C}\right)$ durante $24 \mathrm{~h}$, após o que foram secos superficialmente e pesados na condição de saturado com superfície seca (m2). Por fim, foi determinada a massa do corpo de prova quando imerso em água $(\mathrm{m} 3)$ à temperatura de $\left(23 \pm 5^{\circ} \mathrm{C}\right)$ por meio de balança hidrostática.

O ensaio de caracterização mecânica relativo à resistência a compressão axial foi executado em cada traço desenvolvido, nas idades de 7, 14 e 28 dias. O ensaio ocorreu em ambiente laboratorial com auxílio de uma da prensa Solotest Hidráulica 100t digital, previamente calibrada. Para execução do ensaio, os corpos de prova foram retirados do tanque de cura, previamente secos e posicionados longitudinalmente na prensa de forma centralizada com os pratos da prensa, sendo submetidos a uma carga crescente, a uma razão de $0,5 \pm 0,1 \mathrm{kgf} / \mathrm{cm}^{2}$ até a ruptura conforme item 6.2 .5 da NBR 12118 (ABNT, 2011).

Os resultados dos ensaios previamente descritos foram representados por meio de média e desvio padrão através de três determinações para cada traço produzido.

\section{Etapa 2: produção dos blocos de concreto}

Definida a porcentagem de PET ideal de incorporação, deu-se sequência à produção dos blocos de concreto do tipo vazado, fabricados nas dimensões $14 \times 19 \times 39 \mathrm{~cm}$ (família M-15), produzidos em uma vibroprensa (Figura 3).

Figura 3 - Desforma dos blocos após a sua produção

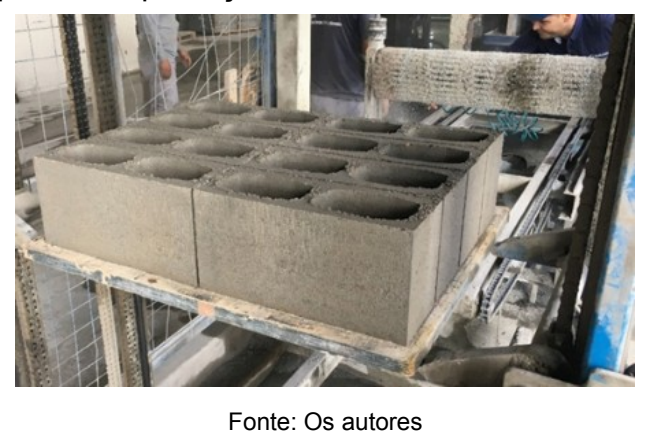

Os blocos de concreto necessitam atender aos requisitos técnicos da análise dimensional, absorção de água, área líquida, ensaio de compressão axial e índice de vazios, visando torná-los adequados à comercialização.

O ensaio de resistência à compressão axial foi executado em seis blocos de cada traço, nas idades de 14 e 28 dias seguindo os procedimentos estabelecidos NBR 6136 (ABNT, 2016). Antes da realização do ensaio foi necessário capear os blocos de concreto, para regularização das faces e melhor distribuição das cargas aplicadas sobre os blocos no momento do ensaio de resistência a compressão. A tensão de ruptura dos blocos (MPa) foi determinada conforme a NBR 12118 (ABNT, 2014). Os valores característicos da resistência a compressão dos blocos de concreto (MPa) foram calculados de 
acordo com a NBR 6136 (ABNT, 2016). Para o ensaio de análise dimensional foram coletadas as dimensões de seis blocos de concreto de cada traço: largura (b); altura (h); comprimento (l); espessura das paredes longitudinais (el); espessura das paredes transversais (et); dimensões dos furos. O valor de cada dimensão do corpo-de-prova foi resultado da média de três determinações executadas em pontos distintos.

Para a espessura das paredes foram realizadas duas determinações em cada parede longitudinal e uma determinação em cada parede transversal, tomadas na face de menor espessura. Para as dimensões dos furos foram retiradas duas determinações no centro aproximado de cada furo do bloco, na direção longitudinal e transversal, tomadas na face de maior espessura do bloco. A espessura mínima da parede longitudinal é resultado da média das determinações feitas no bloco. O cálculo da área bruta foi calculado pelo produto do valor médio das dimensões obtidas de largura e comprimento, sem desconto das áreas dos furos ou reentrâncias. As dimensões foram aferidas com precisão de $1,0 \mathrm{~mm}$ por meio de uso de paquímetro metálico calibrado.

Os ensaios de absorção de água, área líquida, massa específica e índice de vazios foram realizados em três blocos de concreto para cada traço. Para isso, procedeu-se a secagem do corpo de prova por meio de estufa na temperatura de até $\left(110 \pm 5^{\circ} \mathrm{C}\right)$ e mantida essa condição por $24 \mathrm{~h}$. Na sequência, registrou-se por meio de pesagem a massa seca $(\mathrm{m} 1)$ e, com os blocos em temperatura ambiente, os blocos foram imersos em água à temperatura de $\left(23 \pm 5^{\circ} \mathrm{C}\right)$ durante $24 \mathrm{~h}$. Feito isso, os blocos foram secos superficialmente, pesados na condição de saturado com superfície seca $\left(\mathrm{m}^{2}\right)$ e imersos em água $\left(\mathrm{m}^{3}\right)$, por meio de balança hidrostática.

Para obtenção dos resultados da massa específica, absorção de água e índice de vazios, utilizaram-se as Equações 2, 3 4, citadas anteriormente. O cálculo da área líquida de cada bloco, expressa em $\mathrm{cm}^{2}$, foi feita utilizando-se a Equação 5, em que y é a massa específica da água utilizada no ensaio, expressa em $\mathrm{g} / \mathrm{cm}^{3}$; h é a altura média do corpo de prova medida na direção perpendicular à seção de trabalho, expressa em $\mathrm{cm}$.

Aliq $=\frac{\mathrm{m} 2-\mathrm{m} 3}{\mathrm{~h} \times \gamma} \times 1000$

Onde:

$\boldsymbol{Y}=$ massa específica da água utilizada no ensaio, expressa em $\mathrm{g} / \mathrm{cm}^{3}$

$\boldsymbol{h}=\mathbf{a}$ altura média do corpo de prova medida na direção perpendicular à seção de trabalho, expressa em $\mathrm{cm}$

M2 = Massa do corpo de prova na condição de saturado com superfície seca $(\mathrm{g})$

M3 = Massa do corpo de prova quando imerso em água $(\mathrm{g})$

\section{Resultados}

Nota-se que quanto maior a quantidade de substituição de areia industrial por resíduo de PET na matriz cimentícia do concreto, menor é sua massa específica se comparada ao traço RF (referência). Por outro lado, em relação às propriedades de absorção de água e de índice de vazios, percebe-se tendência contrária, ou seja, elevação em relação ao traço RF, com exceção ocorrendo no traço PET10, onde se observou os melhores resultados em termos destes índices em relação ao RF. (Tabela 3). Estes comportamentos podem ser atribuídos às propriedades físicas do PET em particular à densidade da partícula e a sua forma geométrica (lamelar, em contrapartida da esférica observada na areia natural) que diminuem a massa aparente ao mesmo tempo em que aumentam a macroporosidade, à medida que o teor de resíduos se eleva na matriz cimentícia. A maior porosidade também pode estar relacionada a heterogeneidade do material, visto que a interrupção de material homogêneo com certa quantidade de material heterogêneo pode criar grandes espaços de vazios dentro da mistura (LUCOLANO et al., 2013). 
O ensaio de absorção de água indicou que os traços PET5 e PET10 pouco diferiram do traço RF, com o traço PET10 apresentando menor absorção média em relação ao de referência (redução de 4,47\%). O traço com PET15 apresentou altos valores de absorção de água, apontando que seu emprego em blocos é inviável. No ensaio de índice de vazio, os traços apresentaram comportamento similar aos encontrados para absorção de água, uma vez que esses parâmetros estão diretamente relacionados. O teor de substituição de $10 \%$ foi o que proporcionou melhor adensamento entre as partículas, em virtude de ter o menor índice de vazios e proporcionar menor absorção de água na matriz cimentícia (Tabela 3).

Tabela 3: Valores médios e desvio padrão para as propriedades físicas dos traços pesquisados

\begin{tabular}{cccc}
\hline Traço & Massa específica $\left(\mathbf{g} / \mathbf{c m}^{3}\right)$ & Absorção de água (\%) & Índice de vazios (\%) \\
\hline RF & $2,39 \pm 0,027$ & $11,42 \pm 0,006$ & $21,45 \pm 0,008$ \\
\hline PET 5 & $2,37 \pm 0,110$ & $11,84 \pm 0,004$ & $21,91 \pm 0,014$ \\
\hline PET 10 & $2,35 \pm 0,063$ & $10,91 \pm 0,003$ & $20,39 \pm 0,005$ \\
\hline PET 15 & $2,33 \pm 0,079$ & $14,36 \pm 0,008$ & $25,03 \pm 0,016$ \\
\hline
\end{tabular}

Fonte: Os autores

Nota-se elevação da resistência à compressão axial em todos os traços pesquisados para todas as idades ensaiadas (Figura 4). Porém, à medida que se incorporam flakes de PET, observa-se progressiva redução de resistências em relação ao RF. O PET15 apresentou o pior desempenho, com redução de $45,45 \%$ aos 28 dias de idade. Os traços PET5 e PET10 apresentaram desempenhos semelhantes, diferindo-se apenas na idade aos 28 dias, em que o primeiro alcançou resistência superior a mínima requerida $(3,05 \mathrm{MPa})$, atendendo ao critério normativo, com viabilidade para o uso em blocos de concreto sem função estrutural.

Figura 4: Resistência à compressão axial média=desvio padrão dos CPs em função do traço e da idade

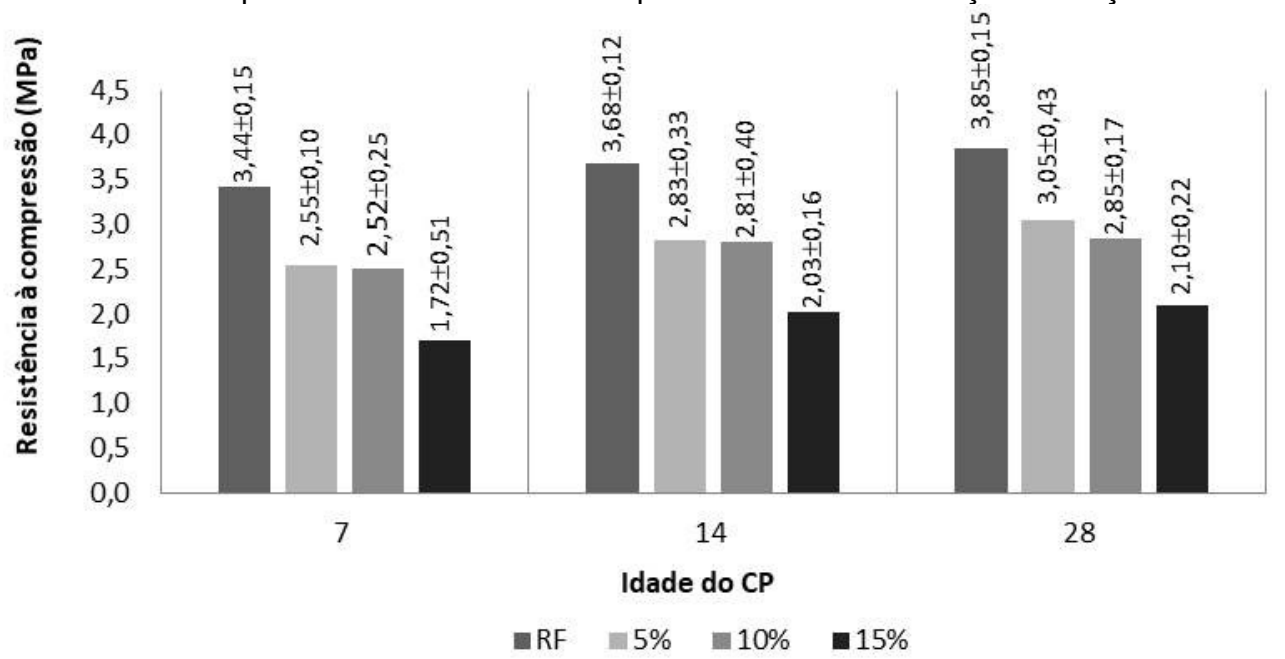

Fonte: Os autores

Foi possível estabelecer correlação entre os teores de incorporação do resíduo de PET e massa específica (Figura 5a), bem como, com a resistência à compressão axial (Figura 5b). As curvas de tendências geradas por meio de análise de regressão linear em ambos os casos forneceram um adequado ajustamento dos dados pesquisados $\left(R^{2}>0,90\right)$. Com o auxílio da primeira correlação, foi possível identificar que o teor de substituição visando atender ao critério de resistência mecânica (3MPa) seria de $7,15 \%$ de incorporação de PET no traço. Já por meio da segunda foi possível observar que a resistência à compressão se reduz à medida que a massa específica dos traços diminui, ou seja, pela substituição de areia artificial por PET. Como aspecto positivo, a diminuição da massa específica 
reduz a massa dos blocos, o que pode implicar em alívio de cargas no sistema estrutural.

Figura 5: Correlação entre (a) o teor de incorporação de PET e (b) massa específica com a resistência média à compressão axial aos 28 dias

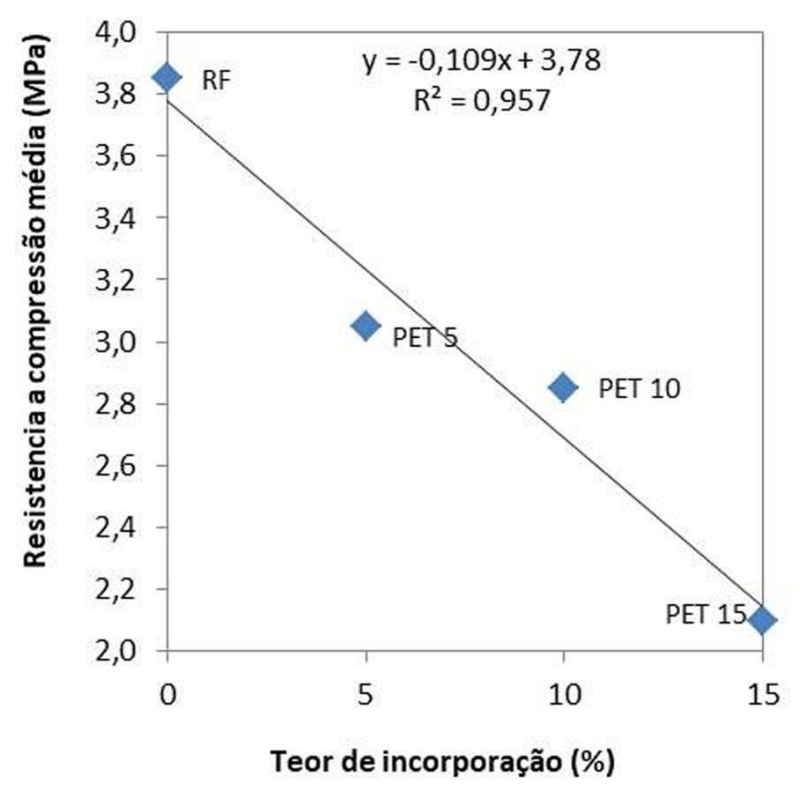

(a)

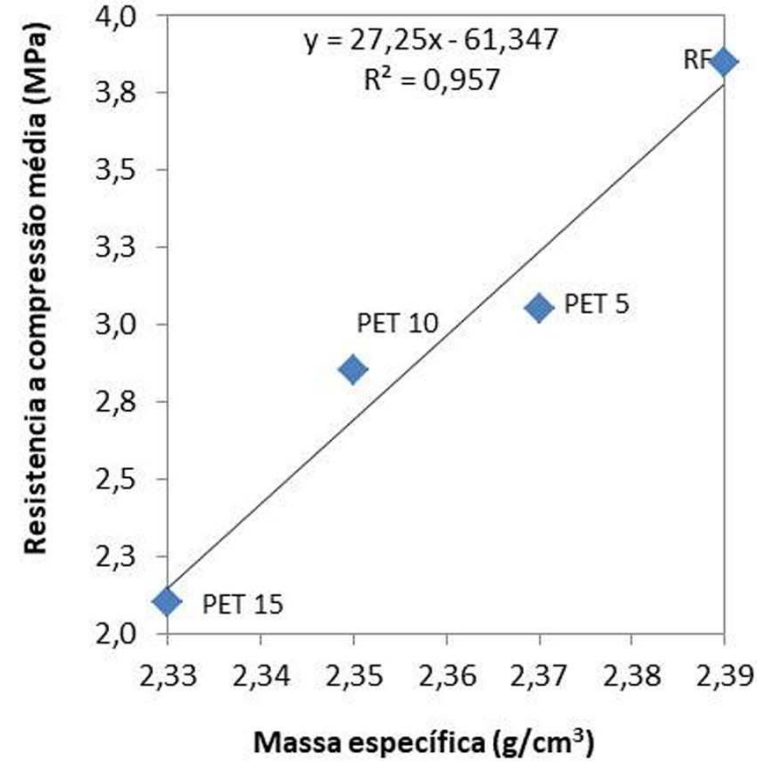

(b)

Fonte: Os autores

A análise estatística indicou que há diferença significativa entre o traço de referência e os traços com incorporação de PET $(p<0,05)$. Já os traços PET5 e PET10 não diferem entre si $(p>0,05)$, mas diferem significativamente do traço PET15 $(p<0,05)$. Portanto, tanto os traços PET5 e PET10 são adequados para a produção do bloco de concreto, apesar da menor resistência alcançada no segundo. Uma vez que o traço PET10 apresentou melhor desempenho em termos de absorção de água e índices de vazios, e que não há diferença significativa em termos de resistência com PET5, optou-se por produzir os blocos com o teor de $10 \%$ de PET, uma vez que essa escolha favorece a incorporação de maior quantidade de resíduos. Essa decisão também se embasa no fato de que nas amostras de blocos produzidas com $10 \%$ de PET, utilizou-se de processo mecanizado (vibroprensado), que permite que se atinja resistência maior que o processo manual, já realizado para o traço no laboratório. Assim, a partir dessa definição, foram produzidos os blocos, cujos resultados dos ensaios são apresentados a seguir.

Sobre o ensaio de análise dimensional, todos os blocos com dimensões nominais de $140 \mathrm{~mm} \times 190 \mathrm{~mm}$ x 390mm (largura, altura e comprimento) satisfazem os requisitos da NBR 6136 (ABNT, 2016), no qual especifica uma tolerância máxima de $\pm 2 \mathrm{~mm}$ para a largura e $\pm 3 \mathrm{~mm}$ para altura e para o comprimento (Tabela 4). Os blocos apresentam valores médios de espessura superiores aos mínimos requisitados pela NBR 6136 (25) para a classe C, com largura nominal de $140 \mathrm{~mm}$, e possuem a menor dimensão do furo igual ou superior a $70 \mathrm{~mm}$ (requerida para blocos de largura nominal $140 \mathrm{~mm}$ ), atendendo às exigências normativas. Acerca da área líquida, os blocos apresentaram valores similares, uma vez que foram confeccionadas com o mesmo molde e na mesma máquina (Tabela 5). A NBR 6136 (ABNT, 2016) ressalva que o bloco vazado de concreto simples, com ou sem função estrutural, deve possuir área líquida igual ou inferior a $75 \%$ da área bruta. Portanto os blocos pesquisados atendem a esse requisito. 
Tabela 4 - Valores médios e desvio padrão das dimensões dos blocos com o traço de referência e PET10

\begin{tabular}{cccccccc}
\hline \multirow{2}{*}{ Traço } & \multicolumn{3}{c}{ Dimensões (mm) } & \multicolumn{2}{c}{ Paredes (mm) } & \multicolumn{2}{c}{ Furos (mm) } \\
\cline { 2 - 7 } & Comp. & Largura & Altura & Long. & Transv. & Long. & Transv. \\
\hline RF & $390,6 \pm 0,50$ & $139,8 \pm 0,26$ & $189,5 \pm 0,16$ & $18,4 \pm 0,16$ & $18,6 \pm 0,14$ & $158,4 \pm 0,34$ & $90,6 \pm 0,84$ \\
\hline PET 10 & $390,5 \pm 0,53$ & $139,8 \pm 0,36$ & $189,6 \pm 0,50$ & $18,6 \pm 0,28$ & $19,1 \pm 0,17$ & $158,7 \pm 0,27$ & $90,8 \pm 0,91$ \\
\hline \multicolumn{6}{c}{ Fonte: Os autores }
\end{tabular}

Tabela 5 - Area bruta e líquida dos blocos produzidos com tração de referencia e PET10.

\begin{tabular}{cccc}
\hline Traço & Área Bruta - $\mathbf{A b}\left(\mathbf{m m}^{2}\right)$ & Área Líquida - $\mathbf{A l ~}\left(\mathbf{m m}^{2}\right)$ & Al/Ab (\%) \\
\hline RF & $54.657,1$ & $25.393,2$ & 46,46 \\
\hline PET 10 & $54.692,1$ & $25.753,4$ & 47,09 \\
\hline
\end{tabular}

Fonte: Os autores

Os resultados de absorção de água mostraram que o traço de referência e o PET10 atendem aos parâmetros normativos de 10\% estabelecido na NBR 6136 (ABNT, 2016) (Tabela 6). Devido ao processo vibroprensagem utilizado na produção dos blocos, os valores de absorção de água foram inferiores a aqueles encontrados no estudo de dosagem. Silva (2016) encontrou absorção de água de $3,7 \%$ para blocos de concreto com incorporação de 10\% de PET micronizado (com características diferentes desta pesquisa), inferior ao encontrado nesse trabalho. Possivelmente isso ocorre, em virtude da relação agregado/cimento utilizado por Silva (2016) uma vez que ela é menor, aumentando o consumo de cimento, que reduz a porosidade capilar do bloco e aumenta sua resistência.

Tabela 6 - Valores médios e desvio padrão da Absorção de água, índice de vazios e massa específica dos blocos de referência e PET10

\begin{tabular}{|c|c|c|c|}
\hline Traço & Absorção de água (\%) & Índice de vazios (\%) & Massa específica $\left(\mathrm{g} / \mathrm{cm}^{3}\right)$ \\
\hline $\mathrm{RF}$ & $8,14 \pm 0,002$ & $17,36 \pm 0,003$ & $2,58 \pm 0,002$ \\
\hline PET 10 & $8,92 \pm 0,002$ & $17,75 \pm 0,003$ & $2,55 \pm 0,011$ \\
\hline
\end{tabular}

Fonte: Os autores

Assim como na etapa de estudo de dosagem, os valores de índice de vazios são proporcionais aos valores de absorção de água, pois quanto menor os vazios existentes na estrutura da matriz cimentícia, menor a quantidade de poros na massa de concreto, ocasionando menor absorção de água (Tabela 6). Como esperado, o processo de vibroprensagem foi eficaz em proporcionar uma estrutura mais coesa a matriz cimentícia, entrosando melhor seus elementos constituintes, o que provoca menor absorção de água. O melhor entrosamento também poderá ocasionar elevação da densidade de massa específica dos blocos, descrito na sequência.

A massa específica se reduziu no traço de PET10 em virtude da menor densidade do resíduo de polietileno tereftalato. Por outro lado, os valores de massa específica são superiores as encontradas no estudo de dosagem, indicando que o processo mecânico de compactação efetivamente proporcionou melhor entrosamento entre as partículas da matriz científica em relação ao processo manual. Este comportamento também ajuda a explicar a menor absorção de água e de índice de vazios encontrados nos traços dos blocos.

Os valores da resistência de compressão axial dos blocos (fbk) foram obtidos desconsiderando-se o desvio-padrão da fábrica, conforme a NBR 6136 (ABNT, 2016), visto que esta pesquisa possui caráter experimental. A incorporação do PET na mistura ocasionou redução da resistência mecânica aos 14 quanto aos 28 dias, similarmente ao que ocorreu no estudo de dosagem (Figura 6). Esse comportamento se assemelha ao observado por Silva (2016), em que a resistência, nas idades de 3, 7 e 28 dias, diminui nos blocos confeccionados com 10\% de PET micronizado. 
Figura 6: Resistência característica à compressão dos blocos em função do traço e idade.

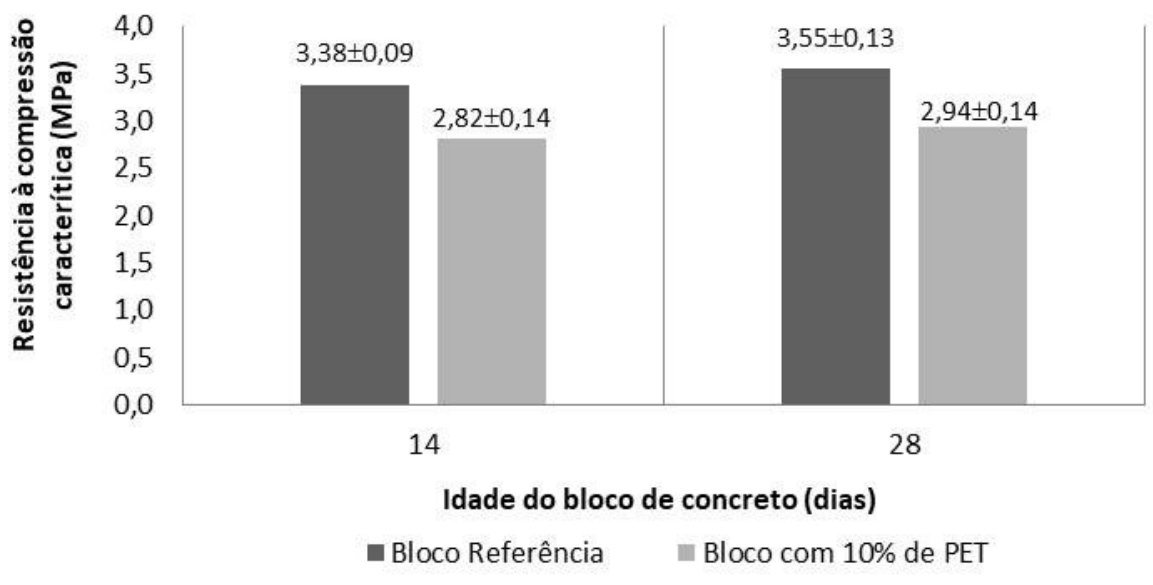

Fonte: Os autores

Apesar da elevação da resistência média dos blocos em relação ao valor encontrado no estudo de dosagem com substituição de $10 \%$ de PET (de 2,85MPa para 2,94MPa), esta não foi suficiente para trazer a resistência característica à compressão acima do parâmetro mínimo normativo proposto pela NBR 6136 (ABNT, 2016), de 3MPa aos 28 dias para blocos classe $C$ sem função estrutural. Algumas razões podem ser elencadas para tal comportamento, como o fato de os polímeros possuírem resistência mecânica inferior aos agregados minerais e a pouca interação entre a PET e a matriz cimentícia. A elevação do índice de vazios na matriz, apesar de a diferença ser pequena em relação ao traço de referência, pode ter aumentado a percentagem de ar incorporado nos blocos, diminuindo, assim, a resistência. Cita-se que outros fatores como dispersão das partículas, sua aglomeração ou ainda sua baixa aderência, bem com a falta de compatibilidade das partículas de PET na matriz cimentícia podem também contribuir para a redução observada, o que requer uma investigação mais detalhada por meio de ensaios específicos não realizados nesta pesquisa (LUCOLANO et al., 2013; MODRO et. al., 2009).

\section{Conclusão}

A presente pesquisa se propôs a avaliar a potencialidade da substituição do agregado miúdo industrial por resíduo de polietileno tereftalato em sua forma triturada para a confecção de concretos secos, visando a fabricação de blocos de concreto não estruturais. Foram considerados os requisitos normativos de resistência à compressão axial, absorção de água, área líquida e controle dimensional, além do índice de vazios e massa específica.

O estudo de traços, com diferentes proporções de incorporação de resíduos de PET em substituição a areia, identificou o traço que proporciona a maior incorporação de resíduo de PET e maior potencial de uso. Concluiu-se que o teor de resíduos de PET na mistura com melhor desempenho mecânico foi o de $5 \%$. Todavia, não houve diferença estatística em relação ao teor de $10 \%$ de incorporação de resíduo, com resultados de absorção de água e índice de vazios mais satisfatórios que o primeiro. Assim, por meio dos ensaios conduzidos, conclui-se que incorporação de PET mais adequada a ser empregada nos blocos de concreto é a de $10 \%$, apesar do não atendimento da resistência mecânica, que se apresentou inferior a $3 \mathrm{MPa}$. Esta decisão foi tomada partindo-se do pressuposto de que o processo mecânico de vibropresagem poderia proporcionar maior entrosamento entres as partículas, elevando a densidade específica do traço, e consequentemente, elevando a resistência mecânica acima do limite normativo, uma vez que o estudo experimental indicou pouca diferença para que isso acontecesse. 
A avaliação das características físicas e mecânicas dos blocos com função não estrutural sem e com substituição de PET no teor de 10\%, foram feitas conforme recomendações da NBR 6136 . A absorção de água, área líquida, analise dimensional, índice de vazios e massa específica atenderam aos requisitos normativos, apresentando valores inferiores aos observados nos ensaios laboratoriais, resultado do processo de produção industrial, uma vez que estão são confeccionados por meio de vibroprensagem.

Quanto ao ensaio mecânico aos 28 dias, as unidades com PET apresentaram redução na resistência à compressão de $17,19 \%$ em relação aos blocos referências, não alcançando a resistência característica pretendida de $3 \mathrm{MPa}$, apesar de o traço ter apresentado resistência superior aos observados em laboratório. No entanto, a elevação alcançada no processo mecanizado não se revelou suficiente para proporcionar aos blocos resistência superior a estipulada em norma. Algumas razões podem ser elencadas para tal acontecimento, como o fato de os polímeros possuírem resistência mecânica inferior aos agregados minerais e a pouca interação entre a PET e a matriz cimentícia. Outro fator pode estar relacionado ao aumento de índice de vazios na matriz, que apesar de a diferença ser pequena em relação ao traço de referência, pode ter aumentado a percentagem de ar incorporado nos blocos, diminuindo a capacidade de resistência. Por meio da correlação entre a porcentagem de substituição de PET e resistência mecânica a compressão, recomenda-se então para trabalhos futuros ou ainda para fins de produçao comercial que o teor de substituição seja reduzido na amostra para cerca de $7 \%$ de PET, fazendo com que o critério de resistência mecânica seja também atendido, tornando o traço viável sob o ponto de vista técnico e de sustentabilidade.

Conclui-se, portanto, que a incorporação de PET nos blocos de concreto é uma alternativa técnica viável com vista a promover a sustentabilidade urbana, ajudando a evitar o lançamento desse material em áreas ilegais e/ou aterros sanitários, corroborando com plano de desenvolvimento sustentável estabelecido na Agenda 2030.

\section{Agradecimentos}

Ao Instituto Federal de Mato Grosso (IFMT) e Universidade Federal de Mato Grosso, pela disponibilização dos laboratórios para a realização dos ensaios.

\section{Referências}

ABIPET. Associação Brasileira da Indústria do PET. $10^{\circ}$ Censo da Reciclagem de PET no Brasil. 2015. [Accessed 30 Octuber 2020]. http://www.abipet.org.br/indexAjax.html? method=baixarArquivo \&id $=548$

AGOPYAN, Vahan; JOHN, Vanderley. M. O desafio da sustentabilidade na construção civil. Goldemberg, J. (Coord.). São Paulo: Edgard Blücher, 2011. 144p. ISBN 978-8521206101

ALBANO, Carmem; CAMACHO, Nelson; HERNANDEZ, Marianella; MATHEUS, A.; GUTIERREZ, A. Influence of content and particle size of waste pet bottles on concrete behavior at different w/c ratios [online]. Waste management, 2009. Vol. 29, n. 10, p. 2707-2716. https://doi.org/10.1016/j.wasman.2009.05.007

ABNT. Associação Brasileira de Normas Técnicas - ABNT. NBR 12118: Blocos vazados de concreto simples para alvenaria - Métodos de ensaio. Rio de Janeiro: 2014. [Accessed 30 Octuber 2020]. Available from: https://www.abntcatalogo.com.br/norma.aspx?ID=314197

NBR 15900-1: Água para amassamento do concreto - Parte 1: Requisitos. Rio de Janeiro: 2009. [Accessed 30 Octuber 2020]. Available from: https://www.abntcatalogo.com.br/norma.aspx? $\mathrm{ID}=57168$ 
NBR 16605: Cimento Portland e outros materiais em pó - Determinação da massa específica. Rio de Janeiro: 2017. [Accessed 30 Octuber 2020]. Available from: https://www.abntcatalogo.com.br/norma.aspx?ID=372002

NBR 16697: Cimento Portland - Requisitos. Rio de Janeiro: ABNT, 2018.

[Accessed 30 Octuber 2020]. Available from: https://www.abntcatalogo.com.br/norma.aspx?ID=400221

NBR 6136: Blocos vazados de concreto simples para alvenaria - Requisitos. Rio de Janeiro: 2016. [Accessed 30 Octuber 2020]. Available from: https://www.abntcatalogo.com.br/norma.aspx?ID=364276

NBR 7211: Agregados para concreto - Especificação. Rio de Janeiro: 2009.

[Accessed 30 Octuber 2020]. Available from: https://www.abntcatalogo.com.br/norma. aspx?ID=40092

NBR 9776: Agregados - Determinação da massa específica de agregados miúdos por meio do frasco Chapman. Rio de Janeiro: 1987. [Accessed 30 Octuber 2020]. Available from: https://www.abntcatalogo.com.br/norma.aspx?ID=79522

NBR NM 248: Agregados - Determinação da composição granulométrica. Rio de Janeiro: 2003. [Accessed 30 Octuber 2020]. Available from: https://www.abntcatalogo.com.br/norma.aspx? ID $=2979$

NBR NM 45: Agregados - Determinação da massa unitária e do volume de vazios. Rio de Janeiro: 2006. [Accessed 30 Octuber 2020]. Available from: https://www.abntcatalogo.com.br/norma.aspx?ID=1674

NBR NM 52: Agregado miúdo - Determinação da massa específica e massa específica aparente. Rio de Janeiro: 2009. [Accessed 30 Octuber 2020]. Available from: https://www.abntcatalogo.com.br/norma.aspx?ID=55817

NBR NM 53: Agregado graúdo - Determinação da massa específica, massa específica aparente e absorção de água. Rio de Janeiro: 2009. [Accessed 30 Octuber 2020]. Available from: https://www.abntcatalogo.com.br/norma.aspx?ID=9647

NBR 11768: Aditivos para concreto de cimento Portland. 2. ed. Rio de Janeiro, 2019. [Accessed 30 Octuber 2020]. Available from: https://www.abntcatalogo.com.br/norma.aspx?ID=430826

ABNT. Associação Brasileira de Normas Técnicas. NBR NM 27: Agregados - Redução da amostra de campo para ensaios de laboratório. Rio de Janeiro: 2001. [Accessed 30 Octuber 2020]. Available from: https://www.abntcatalogo.com.br/norma.aspx?ID=3061

BRASIL. Conselho Nacional do Meio Ambiente - CONAMA. Resolução n 313, de 29 de outubro de 2002. Dispõe sobre o inventário nacional de resíduos sólidos industriais. Brasília: Diário Oficial da União, 22 de novembro de 2002. [Accessed 20 September 2020]. http://www.iap.pr.gov.br/arquivos/File/Legislacao/residuos/CONAMA3132002.pdf

BRASIL. Fundação Nacional de Saúde - FUNASA. Programas municipais de coleta seletiva de lixo como fator de sustentabilidade dos sistemas públicos de saneamento ambiental na Região Metropolitana de São Paulo [online]. Brasília: Fundação Nacional de Saúde, 2010.

[Accessed 20 September 2020].

http://www.funasa.gov.br/documents/20182/39040/Programas+municipais+de+colata+seletiva+de+lixo. ..+sao+paulo.pdf/c5d213c8-0e62-492e-ad96-d0efad398efa

CALLEJAS, Ivan Julio Apolonio; DURANTE, Luciane Cleonice; OLIVEIRA, Angela Ssantana. Thermal resistance and conductivity of recycled construction and demolition waste (RCDW) concrete 
blocks. Revista REM [online], 2017. Vol. 70, p. 167-173, 2017. http://dx.doi.org/10.1590/037044672015700048

CAMPOS, Cassio Fabian Sarquis; ALTRAN, Daniele Araujo; FIDELIS, Guilherme Noboru Sassaki; OLIVEIRA, Leonardo Borges. Análise das propriedades físicas do concreto obtido com uso de Polietileno Tereftalato (PET). Colloquium exactaruim, 2014. Vol. 6, n. 4, p. 31-39.

https://revistas.unoeste.br/index.php/ce/article/view/1236

CARDOSO, Alceu Aparecido. Desempenho termo físico e mecânico de argamassas de revestimento produzidas com resíduos sólidos poliméricos, minerais e vegetais. Mestrado. UFMT, 2017.

CORREA, Priscila Marques. Estudo comparativo da influência da adição de PET e PP pósconsumo na produção do concreto estrutural [online]. Mestrado. UFRG, 2015. Available from: https://www.lume.ufrgs.br/handle/10183/130090

DAMASCENO, Flavio Alves; MACEDO, Otávio Assunção Peito; OLIVEIRA, Jofran Luiz; OLIVEIRA, Carlos Eduardo; BRANDÃO, Leidimar Freire. Propriedades Físicas, Mecânicas e Térmicas de Telhas de Concreto Fabricadas com Adição de Diferentes Materiais Isolantes. Engenharia na agricultura [online], 2015. Vol. 23, n.5, p. 406-417. https://doi.org/10.13083/reveng.v23i5.578

FERNANDES, I. D. Blocos e Pavers: Produção e controle de qualidade. 8a. ed. São Paulo: Treino Assessoria e Treinamentos Empresariais Ltda. 2016. 200p.

GOMES, Paulo Cesar Correia; PEREIRA, Fábio Alencar, UCHÔA, Silvia Beatriz Beger, OLIVEIRA, Fábio Cabral; ALMEIDA, Licia Holanda. Obtenção de blocos de concreto com utilização de resíduos reciclados da própria fabricação dos blocos. Ambiente Construído [online], 2017. Vol.17, n.3, p. 267-280. https://doi.org/10.1590/s1678-86212017000300175

LU, Weisheng; TAM, Vivian. Construction waste management policies and their effectiveness in Hong Kong: A longitudinal review. Renewable and Sustainable Energy Reviews [online], July 2013. Vol.23, p. 214-223. https://doi.org/10.1016/j.rser.2013.03.007

LUCOLANO, Fabio; LIGUORI, Barbara; CAPUTO, Domenico; COLANGELO.F; CIOFFI. Raffaele. Recycled plastic aggregate in mortars composition: Effect on physical and mechanical properties [online]. Materials and Design, 2013. Vol.52, n.1, p. 916-922. https://doi.org/10.1016/j.matdes.2013.06.025

MODRO, N.L.R. et al. Avaliação de concreto de cimento Portland contendo resíduos de PET. Matéria (Rio de Janeiro) [online]. 2009, v. 14, n. 1 [Acessado 14 Junho 2021] , pp. 725-736. Disponível em: <https://doi.org/10.1590/S1517-70762009000100007>. Epub 11 Maio 2009. ISSN 1517-7076. https://doi.org/10.1590/S1517-70762009000100007.

NAVARRO, Raunavi; FERRANDIZ, Santiago; LOPEZ Juan; SEGUİ, Vicente Jesus. The influence of polyethylene in the mechanical recycling of polyethylene terephthalate. J Mater Process Techno I[online], 2008. vol. 195, p. 110-6. https://doi.org/10.1016/j.jmatprotec.2007.04.126

ONU. Organização das Nações Unidas. Transformando Nosso Mundo: A Agenda 2030 para o Desenvolvimento Sustentável. 2015. [Accessed 30 Octuber 2020]. http://nacoesunidas.org/pos2015/agenda2030/

PAVLU, Tereza; FORTOVA, Kristina; DIVIS, Jakub; HAJEK, Petr. The Utilization of Recycled Masonry Aggregate and Recycled EPS for Concrete Blocks for Mortarless Masonry. Materials (Basel, Switzerland) [online], 2019. Vol.12, n. 2, p. 1-18. https://doi.org/10.3390/ma12121923 
PNUD. Programa das Nações Unidas para o Desenvolvimento. Buildings: investing in energy and resource efficiency. In: Towards a Green Economy: pathways to sustainable development and poverty eradication, 2012. [Accessed 30 Octuber 2020]. http://eprints.Ise.ac.uk/47895/

SILVA, José Bezerra. Avaliação do desempenho de blocos de concreto estrutural dosados com Politereftalato de etileno (PET) micronizado. Doutorado. UFCG, 2016. Available from: http://dspace.sti.ufcg.edu.br:8080/jspui/handle/riufcg/952

\section{Pâmella Mirélla de Souza Schilive}

Pós-graduanda em Desenvolvimento Urbano pelo Instituto Federal de Educação, Ciência e Tecnologia de Mato Grosso, Campus Várzea Grande, graduação em Engenharia Civil pela Universidade Federal de Mato Grosso, Campus Cuiabá (2019) e formação técnica no curso de Edificações pelo Instituto Federal de Educação, Ciência e Tecnologia de Mato Grosso, Campus Cuiabá (2013).

Contribuição de coautoria: Execução de toda a metodologia do artigo, bem como escrita do mesmo.

\section{Ivan Julio Apolonio Callejas}

Graduado pela Universidade Federal de Mato Grosso (1995). Mestre pela Faculdade de Engenharia Civil, área de concentração Estruturas, Universidade Estadual de Campinas (1998). Doutor pelo programa de pós-graduação em Física Ambiental na área de conforto ambiental (2012). Atualmente é professor Associado II da Universidade Federal de Mato Grosso, atuando no Departamento de Arquitetura e Urbanismo, tendo atuado como docente do Curso de Pós-Graduação em Engenharia de Edificações e Ambiental (PPGEEA). Integra como colaborador o curso de Mestrado Profissional em Propriedade Intelectual e Transferência de Tecnologia para Inovação (PROFNIT). É líder do Grupo de Pesquisa em Dinâmica Ambiental e Tecnologia (GPDAT). Atuou como bolsista do CNPq, na modalidade EXP (extensão no país), no Programa Agentes Locais de Inovação (ALI) do SEBRAE-MT, de 2014 a 2016. Tem experiência na área de Arquitetura/ Engenharia Civil e interesse na área de tecnologia do ambiente construído, com enfoque na sustentabilidade, voltados ao desempenho termoenergético das edificações e desenvolvimento de materiais, produtos e processos construtivos inovadores.

Contribuição de coautoria: Orientador da pesquisa, revisão do artigo e elaboração dos gráficos.

\section{Luciane Cleonice Durante}

Possui graduação em Engenharia Civil (1993), especialização em Engenharia de Segurança do Trabalho (1994), mestrado em Educação e Meio Ambiente (2000) e doutorado em Conforto Ambiental (2012), ambos pela Universidade Federal de Mato Grosso. Atualmente é Professor Associado IV do Departamento de Arquitetura e Urbanismo da Faculdade de Arquitetura, Engenharia e Tecnologia/UFMT, docente e coordenadora do Programa de Pós-Graduação em Propriedade Intelectual e Transferência de Tecnologia para Inovação (PROFNIT), Coordenadora do Laboratório de Tecnologia e Conforto Ambiental (LATECA), Vice Coordenadora do Grupo de Pesquisa em Tecnologia e Arquitetura Ambiental (GPTAA) e membro do Grupo de Pesquisa em Dinâmica Ambiental e Tecnologia (GPDAT). Coordena a Rede de Parceiros Externos do Parque de Inovação e Sustentabilidade do Ambiente Construído (PISAC), da Universidade de Brasília e integra a Rede Sustenta como representante da UFMT. Atuou como bolsista do CNPq, na modalidade EXP (extensão no país), no Programa Agentes Locais de Inovação (ALI) do SEBRAE-MT, de 2012 a 2014. Atualmente, é Monitora no Programa de Qualificação para Exportação PEIEX- MATO GROSSO 20212022. Possui interesse pela área de inovação, sustentabilidade e resiliência do ambiente construído.

Contribuição de coautoria: Orientadora da pesquisa, revisão do artigo e elaboração dos gráficos. 


\section{Emeli Lalesca Aparecida da Guarda}

Graduada em Arquitetura e Urbanismo (2017) na Universidade de Cuiabá (UNIC), Mestre em Engenharia de Edificações e Ambiental (2019) na Universidade Federal de Mato Grosso (UFMT) e Doutoranda em Arquitetura e Urbanismo (em andamento) na Universidade Federal de Santa Catarina (UFSC). Atualmente, participa de pesquisas do Laboratório de Tecnologia e Conforto Ambiental (LATECA) da Universidade Federal de Mato Grosso (UFMT) e da Universidade de Brasilia (UNB), voltadas para à áreas de: mudanças climáticas, eficiência energética, desempenho térmico de edificações e zoneamaento bioclimático brasileiro, habitações de interesse social, conforto térmico e adaptativo. E atua como pesquisadora de doutorado no Laboratório de Conforto Ambiental (Labcon/UFSC). Possui experiências com simulações computacionais no âmbito de desempenho termoenergético.

Como citar: SCHILIVE, Pâmella M. S., CALLEJAS, Ivan Julio A., DURANTE, Luciane C" GUARDA, Emeli L. A.. Blocos de concreto com resíduos de PET: Alternativa para a Sustantabilidade Urbana. Revista Paranoá. n.31. Jul/dez de 2021. DOI: http://doi.org/10.18830/issn.1679-0944.n31.2021.03

Editor responsável: Daniel Sant'Anna 